\title{
PCSK9 GENE PARTICIPATES IN THE DEVELOPMENT OF PRIMARY DYSLIPIDEMIAS
}

\author{
Matías-Pérez $\mathrm{D}^{1}$, Pérez-Santiago $\mathrm{AD}^{1}$, Sánchez Medina $\mathrm{MA}^{1}$, Alpuche Osorno JJ², García-Montalvo IA ${ }^{1}$ \\ *Corresponding Author: Dr. Iván A. García-Montalvo, Division of Postgraduate Studies and Research, \\ Tecnológico Nacional de México/Instituto Tecnológico de Oaxaca, Oaxaca City, Oaxaca, México. Av. \\ Víctor Bravo Ahuja No. 125, Esq. Calzada Tecnológico Oaxaca, Oaxaca. Tel./Fax: +52-951-501-5016. \\ E-mail: ivan.garcia@itoaxaca.edu.mx
}

\begin{abstract}
Dyslipidemias are a group of diseases, which are characterized by abnormal blood concentrations of cholesterol, triglycerides and/or low-density lipoprotein-cholesterol (LDL-c). Dyslipidemia is a determinant condition for the progress of an atherosclerotic plaque formation. The resulting atherogenicity is due to at least two mechanisms: first, to the accumulation in the plasma of lipid particles that have the capacity to alter the function of the endothelium and deposit at the atheromatous plaque, and second, at an insufficient concentration of multifactorial type of high density lipoprotein-cholesterol (HDL-c), whose function is to protect against the development of atherosclerosis. Its highest prevalence is encountered among individuals with diabetes, hypertension or overweight. Hyperlipidemia is one of the main predisposing factors for the development of cardiovascular disease. Hyperlipidemia can be the result of a genetic condition, the secondary expression of a primary process or the consequence of exogenous factors (food, cultural, socio-economic, etc.), all of which lead to the elevation of plasma lipid levels. The objective of this study was to carry out an analysis of the genes involved in the development of dyslipidemias that lead to cardiovascular disease with special emphasis on the proprotein convertase subtilin/kexin type 9 (PCSK9) gene. The PCSK9 gene participates in the development of primary dyslipidemias, mainly familial hypercholesterolemia, currently the pharmacological treatment of choice to reduce

\footnotetext{
${ }^{1}$ Division of Postgraduate Studies and Research, Tecnológico Nacional de México, Instituto Tecnológico de Oaxaca, Oaxaca City, Oaxaca, México Universidad Autónoma "Benito Juárez" de Oaxaca, Oaxaca City, Oaxaca, México
}

${ }^{2}$ Faculty of Medicine and Surgery, Facultad de Medicina y Cirugía,
\end{abstract}

LDL-c are statins, however, it has been observed that these have been insufficient to eliminate cardiovascular risk, especially in subjects with primary forms of hypercholesterolemia related to genetic mutations, or statin intolerance.

Keywords: Cardiovascular diseases; Dyslipidemia; Hyperlipidemia; Proprotein convertase subtilisin/kexin type 9 (PCSK9) gene

\section{INTRODUCTION}

Cardiovascular diseases (CVDs) are considered the leading cause of death in Mexico and worldwide [1,2]. According to the WHO website, in 2016 alone, CVDs produced an estimate of 17.9 million deaths [2]. Strikingly, $82.0 \%$ of the 16 million deaths due to non-communicable diseases that occur in people under 70 years of age, take place in low and middle income countries. And in turn, $37.0 \%$ of such events find their origins in CVDs [1]. In particular, atherosclerotic CVDs, namely ischemic heart disease and cerebrovascular disease, account for the greater part of CVD mortality, even if the trend has been decreasing throughout the last decades [3-5]. Amid the principal risk factors for CVD, we can list a sedentary lifestyle, excessive consumption of saturated fats, smoking, diabetes mellitus (DM) and high blood pressure [6]. Although hypertension is, globally, the risk factor with the largest attributable risk for CVD mortality [3], it is well known that hypertension and dyslipidemia act in a synergistic way on the pathophysiology of atherosclerotic CVDs [7]. In fact, dyslipidemia is regarded as a prerequisite for the maturation of an endothelial primary lesion into an atheromatous plaque $[8,9]$. Thus, the detection and treatment of plasmatic lipid alterations are key to the prevention and management of chronic non-communicable diseases.

Dyslipidemias are defined as a set of diseases caused by abnormal concentrations of blood lipoproteins. They 
are considered metabolic disorders that are largely conditioned by environmental factors, lifestyles, metabolic problems associated with obesity, insulin resistance and DM. Yet, some forms of dyslipidemias appear to be more frequent in direct relatives of dyslipidemic individuals, compared with the general population [10]. The most common dyslipidemias are characterized by low levels of cholesterol bound to high-density lipoprotein (HDL-c) and elevation of tri-glyceride (TG) levels. Interestingly, the ratio between TGs and HDL-c can be an indicator of the presence of resistance to insulin [11]. Cholesterol transported by low-density lipoproteins (LDL-c) seem to play a crucial role in the development of atherosclerotic diseases. Evidence points at a strong correlation between LDL-c hypercholesterolemia and atherosclerotic CVDs $[12,13]$. Atherogenicity is due to at least two mechanisms: first, to the accumulation in the plasma of particles that have the ability to alter the function of the endothelium and can be deposited at the atheromatous plaques, and second, to an insufficient concentration of particles that protect against the development of atherosclerosis [12-14].

Dyslipidemias can be classified according to the criteria established by the WHO and divided into primary and secondary (see Table 1). Primary dyslipidemias are those that occur due to genetic conditions affecting apolipoproteins, their receptors or enzymes implicated in lipid metabolism $[10,15]$. On the other hand, secondary dyslipidemias are produced by acquired alterations in the function of some of these components owing to the type of diet, associated pathologies or drug consumption $[12,13]$. The present review aims to analyze the contribution of genetic factors on the origins of primary dyslipidemias, with special focus on the proprotein convertase subtilin/ kexin type 9 (PCSK9) gene.

PCSK9 Biology Overview. In humans, the PCSK9 gene is located on the short arm of chromosome 1 at a locus correlated with familial hypercholesterolemia (FH), a highly prevalent form of autosomal dominant hyper- cholesterolemia (ADH) $[16,17]$. The PCSK9 gene is a serine protease that promotes the internalization and later lysosomal degradation of the LDL receptor (LDLr), for the most part, in the liver tissue $[18,19]$. The principal action of PCSK9 is too direct $L D L r$ toward lysosomal degradation, thereby reducing $L D L r$ expression at the cell surface and increasing plasma LDL-c levels, carriers of loss-of-function PCSK9 variants have lower plasma LDL-c levels, $P C S K 9$ might also regulate other receptors such as $A P O E 2 R, C D 36$, and very low-density lipoprotein receptor $(V L D L r)$ gene [20]. As a consequence, LDL-c does not clear optimally, which ultimately manifests as an increase in plasmatic LDL-c levels [21]. Lung and liver stand as the main sources of PCSK9 [22], where it is synthesized to be later secreted into the bloodstream $[23,24]$. Because of its role in cholesterol metabolism, $P C S K 9$ rapidly enticed the attention as a therapeutic target $[25,26]$. Currently, PCSK 9 inhibitors are recommended, besides statins, in order to lower LDL-c levels in both primary and secondary prevention regimes for individuals with high risk of atherosclerotic CVDs [27]. Regarding diagnosis and prognosis, PCSK9 levels tend to be higher in coronary artery disease (CAD) patients than in healthy controls, when considering confounding factors [28]. In that same line, it has been suggested that PCSK9 plasma levels could be a strong predictor of coronary arteries calcification [29]. In patients with suspected acute coronary syndrome, PCSK9 levels appeared elevated only when vascular lesions were confirmed, assessed by coronary angiography [30]. And what is more, the severity of CAD correlates robustly with $P C S K 9$ concentrations, in a model incorporating lipid or inflammation indices as mediator variables [28]. Thus, in addition to its involvement on the LDLr lifecycle, PCSK9 also seems to play an important role controlling inflammatory status and, therefore, atherosclerosis risk [31].

PCSK9 Mutations Related to Familial Hyperlipidemia. As expected, alterations in PCSK9 gene are related

Table 1. Classification of hyperlipoproteinemias based on the criteria established by the World Health Organization.

\begin{tabular}{|l|l|l|l|}
\hline Electrophoresis & Lipoproteins & Lipids & Diagnosis \\
\hline chylomicron band at the origin & fasting chylomicronemia & triglycerides; cholesterol & familial hyperchylomicronemia (type I) \\
\hline$\beta$ band increased & LDL increased & cholesterol & $\begin{array}{l}\text { isolated or severe hypercholesterolemia } \\
\text { (type IIA) }\end{array}$ \\
\hline pre $\beta$ band; $\beta$ increased & VLDL; LDL increased & cholesterol; triglycerides & combined hyperlipidemia (type IIB) \\
\hline$\beta$ floating band & $\begin{array}{l}\beta \text {-VLDL } \\
\text { (residual chylomicrons; IDL) }\end{array}$ & triglycerides; cholesterol & $\begin{array}{l}\text { hyperlipidemia mixed } \\
\text { (type III) }\end{array}$ \\
\hline pre $\beta$ band increased & VLDL & triglycerides & $\begin{array}{l}\text { isolated or severe hypertriglyceridemia } \\
\text { (type IV) }\end{array}$ \\
\hline $\begin{array}{l}\text { band of chylomicrons; } \\
\text { pre } \beta \text { increased }\end{array}$ & chylomicrons; VLDL & triglycerides; cholesterol & hypertriglycerdemia (type V) \\
\hline
\end{tabular}

LDL: low-density lipoprotein; VLDL: very-low-density lipoprotein; IDL: intermediate density lipoprotein. 
to dyslipidemias and atherosclerotic CVDs. In a general fashion, gain-of-function mutations of $P C S K 9$ lead to high levels of circulating LDL-c and enhanced risk of CVD [32], whereas nonsense loss-of-function mutations have the opposite effect [33-35]. In 2003, a pioneering study by Abifadel et al. [36] identified two missense mutations of the PCSK9 gene that were linked to ADH in French families, in which alterations at $L D L r$ and $A P O B$ genes were previously discarded. Since that seminal study, a number of subsequent genetic and clinical investigations have associated a defective $P C S K 9$ gene with several forms of FH, characterized by a dominant inheritance pattern. First, a variant was identified in an American Utah kindred, which was produced by a single nucleotide exchange at the seventh exon of the PCSK9 gene sequence that resulted in the missense D374Y substitution [37]. This was motivated by a previous report that unveiled a linkage between $\mathrm{FH}$ and the chromosome 1p32 locus, where the PCSK9 gene is located [38]. In a parallel manner, the Utah D374Y along with the N157K substitutions were found in a sample of Norwegian FH patients [39]. Consistent with these reports, the D374Y mutation was later found in English families, correlating with a serious dyslipidemic profile [40]. Remarkably, at that same codon, a point mutation led to the D374H substitution in two Portuguese FH patients [41]. Later on, four more mutations were encountered in the French population, three of them in highly conserved residues located in the catalytic domain of PCSK9. However, only R218S could be properly linked to $\mathrm{ADH}$, according to DNA family members samples as well as to the clinical history of the family [42]. Notably, the S127R mutation, originally described in the French population [35], was also observed in South African families, which exhibited a FH phenotype [43]. And in New Zealand, two variants (D129G, A168E) were associated with FH and family history of CVD. Intriguingly, both S127R and D129G forms were found unable to be secreted by $\mathrm{HuH} 7$ cells, suggesting that these mutated forms of PCSK9 might bind to LDLr at the intracellular compartment [43]. Furthermore, 24 PCSK9 variants were reported as specific for the Japanese population, with some of them segregated to either low or high LDL-c groups [34].

As depicted in Figure 1 of the study by Hopkins et al. [32], there are a variety of regions implicated in missense gain-of-function mutations of PCSK9, each of them expressing a different degree of severity in LDL-c dysregulation. A quick inspection of such a figure allows one to acknowledge that defects in exons 2 and 7 produce the stronger effects [32]. Notwithstanding the wide heterogeneity of missense mutations, they all seem to share common clinical manifestations, encompassing tendon xanthomas, premature myocardial infarction and stroke
[44]. Recently, in addition to missense mutations, copy number variations of the PCSK9 gene have been recently associated with FH. The duplication of the whole gene conducted to the highest PCSK9 plasma concentration ever reported, being nearly $5000 \mathrm{ng} / \mathrm{mL}$ in one of the cases, accompanied by a pronounced dyslipidemia [45]. And even in normolipidemic subjects, a polymorphism affecting the 3 ' untranslated region of the PCSK9 gene, correlate with lower circulating HDL-c, interestingly, with no effect over LDL-c [46].

PCSK9 and Familial Hyperlipidemia Genetic Heterogeneity. As a cause of ADH, PCSK 9 defects remain relatively rare compared with mutations affecting LDLr or apolipoprotein B100 (apoB-100). For the most part, FH cases are attributed to altered variants of $L D L r$, followed far behind by $A P O B, P C S K 9$ as well as other genes. Roughly, such proportion is essentially similar across different populations including those found in Mexico and Latin America [47,48], US and Canada [49], Portugal [41], Gran Canaria Island in Spain [50], Lebanon [51] and Taiwan [52], just to quote a few examples. But though uncommon, the ample diversity of PCSK9 mutants and polymorphic forms could be a determinant for the differences found in cholesterol metabolisms across populations, even in a more dynamic manner than $L D L r$ or apo-B100 [44]. Of note, a more aggressive form of $\mathrm{ADH}$ is related to PCSK9 compared with either defective $L D L r$ or apoB-100, reflecting as comparatively increased levels of both total plasma cholesterol and LDL-c, and possibly, premature development of atherosclerotic CVDs [32,40,41]. Even more pronounced dyslipidemias derive from mutations affecting multiple genes. Indeed, individuals carrying double mutations in both $L D L r$ and PCSK9 display a more severe dyslipidemic phenotype than simple heterozygotes for mutated forms of $L D L r$, resembling the phenotype resulting from the homozygous $L D L r$ founders $[53,54]$. In contrast, a leucine in-frame insertion in PCSK9 exon 1 seems to partially counteract $L D L r$ defects [51]. And not surprisingly, homozygous carriers of $P C S K 9$ gain-of-function mutations show larger elevations of LDL-c plasma levels, in comparison with heterozygotes [54].

Animal Models of Familial Hyperlipidemia Carrying Altered Types of PCSK9. Of paramount importance for the study of dyslipidemias, genetically engineered animal models have been shown to be able to recapitulate in some respects the phenotype found in $\mathrm{FH}$ human patients, when PCSK9 is altered. For instance, when human PCSK9 carrying the D374Y Utah mutation was stably expressed in either mice or hamsters, animals clearly developed hypercholesterolemia followed by atherosclerotic lesions in the aorta and its branches $[55,56]$. 
Using a similar approach, overexpression of the mutated murine D377Y-PCSK9 led to decreased hepatic LDLr, hyperlipidemia, vascular calcification and collagen deposition at atheromatous plaques [57]. In opposition, PCSK9 knock-out mice developed $74.0 \%$ less aortic cholesterol accumulation than their wild type counterparts after 12 months of western diet exposure. Moreover, PCSK9 knock-out seemed to prevent, in great measure, atherosclerosis due to the lack of apolipoprotein E [58].

Very similar outcomes were obtained in studies performed in swine models. Transgenic Yucatan minipigs carrying human PCSK9-D374Y exhibited reduced hepatic $L D L r$ receptors, accompanied by severe hypercholesterolemia that mostly affected the LDL-c fraction [59]. Under a high-fat, high-cholesterol regime, transgenic pigs presented with rapidly progressing atheromatous plaques in aorta and iliofemoral arteries, with pathological characteristics mimicking human atheromas [59]. Likewise, Ossabaw minipigs expressing primate PCSK9-D374Y and subjected to an atherogenic diet scheme showed early atherosclerosis and endothelial dysfunction at aorta, coronary and renal arteries, as a consequence of a pronounced dyslipidemia [60,61].

Candidate Genes with Active Participation in the Development of Primary Dyslipidemias. The most common genetic disorder of HDL-c is familial hypoalphalipoproteinemia (FHA) (HDL-c levels between 20 and $40 \mathrm{mg} / \mathrm{dL}$ ) and a family history of low HDL-c levels in at least one first-degree relative. The metabolic etiology in many cases appears to be accelerated catabolism of HDL and its apolipoproteins, and some subjects, but not all, are characterized by small, lipid-poor HDL particles and defective lipid efflux. Familial hypoalphalipoproteinemia was previously considered to be a dominant disorder due to mutations in the $A B C A 1$ gene in some families and of unknown genes in other families. Several monogenic disorders of extremely low HDL-c levels have also been described. Although these monogenic causes are rare, and together, they may explain only a small portion $(1.0 \%)$ of low HDL-c cases in the general population, they have demonstrated that extremely low HDL-c levels influence multiple organs, and thus, the clinical significance of HDL deficiency extends beyond cardiovascular risk [62-64].

$A P O B$ Gene. ApoB-100 is a component of $L D L$ located at 2p24-p23; the $A P O B$ gene is made up of 29 exons and encodes two main isoforms of $A p o B$ (see Table 2), ApoB-48 and ApoB-100. When $A p o B$ is damaged, LDL-c cannot bind to $L D L r$, and in consequence, LDL-c levels remain elevated in the bloodstream [65]. In contrast with PCSK9, there is a limited but important number of mutations in ApoB-100 that can lead to FH. Of these, the R3500Q is the most important [66]. In Europe, only $2.5 \%$ of the FH cases are due to $A p o B$ defects [67]. For the eastern population, the R3500Trp variant is the most common [68].

LDLRAP1/ARH (autosomal recessive hypercholesterolemia) Gene. In opposition to $L D L r, A P O B$ and $P C S K 9$, the LDL receptor gene adapted to protein 1 ( $L D L R A P 1)$ is responsible for a type of hypercholesterolemia inherited following an autosomal recessive pattern. For these reasons, $L D L R A P 1$ is also known as the $A R H$ gene, [36]. The $L D L R A P 1$ gene is located at chromosome 1p36-35 [69], made up of nine exons that encode a protein of 308 amino acids. In the ARH, the internalization of the ligand-receptor complex (APOB-LDLr) is not carried out, which produces $L D L r$ accumulating at the cell membrane. Despite the aforementioned, it is much less frequent to find cases of $\mathrm{FH}$ compared with $\mathrm{ADH}$, the number of cases reported to date does not exceed 100 [70]. These cases have been found in Lebanese, Mexican, Japanese, Indian, English, Turkish, American and Syrian populations $[71,72]$.

APOE Gene. As $A p o B$, apolipoprotein E $(A p o E)$ is also a structural component of LDL. The $A p o E$ gene is located at chromosome 19q13.32, made up of four exons. It has been found that damage to apolipoprotein B may be associated with hyperlipoproteinemia type 3, Alzheimer's disease, lipoprotein glomerulopathy and FH, causing, in the latter, an excessive deposit of cholesterol in the tis-

Table 2. Genes involved in the development of dyslipidemias.

\begin{tabular}{|l|l|l|}
\hline Gene & Locus & Phenotype \\
\hline$P C S K 9$ & $1 \mathrm{p} 32$ & related to autosomal dominant HAD and elevation of blood cholesterol levels \\
\hline$A P O B$ & $2 \mathrm{p} 24-23$ & increase in blood cholesterol \\
\hline LDLRAP1/ARH & $1 \mathrm{p} 36-35$ & related to autosomal recessive HAR and accumulation of LDL receptor in cell membranes \\
\hline$A P O E$ & $19 \mathrm{q} 13.32$ & $\begin{array}{l}\text { associated with hyperlipoproteinemia type 3, Alzheimer's disease, lipoproteic glomerulopathy } \\
\text { and familial hypercholesterolemia }\end{array}$ \\
\hline$L D L r$ & $19 \mathrm{p} 13.1-13.3$ & associated with familial hypercholesterolemia \\
\hline$A B C G 5$ and $A B C G 8$ & $2 \mathrm{p} 21$ & both genes are related to the appearance of sitosterolemia \\
\hline
\end{tabular}

HAD: dominant hypercholesterolemia; HAR: recessive hypercholesterolemia; LDL: low-density lipoprotein. 
sues, due to the binding, internalization and catabolism of lipo-proteins, behaving as a ligand of the LDL receptor in liver tissues, the best-known mutation being Leu167del [72-74].

LDLr Gene. The $L D L r$ is located on the short arm of chromosome 19 (p13.1-13.3) and consists of 18 exons and 17 introns [75]. Point mutations present in this gene can affect the functionality of the developed protein, however, mutations can occur that affect the promoter of the gene, preventing it from being transcribed, and thereby interrupting the synthesis of the protein; other mutations include substitutions and those that affect the cytoplasmic domain of the receptor, thus preventing your internalization. Mutations of the $L D L r$ gene associated with problems such as FH are divided into five classes, if the synthesis of $L D L r$, its transport, its union, its internalization or its recycling does not work correctly, there will be an accumulation of cholesterol in the blood, facilitating the formation of atheromatous plaques, xantales, tendinous xanthomas and corneal arches [76-80].

$\boldsymbol{A B C G} 8$ and $\boldsymbol{A B C G} 5$ Genes. The $A B C G 8$ and $A B C G 5$ genes, each consisting of 13 exons, are located on chromosome $2 \mathrm{p} 21$; both genes are related to the appearance of sitosterolemia, which is a rare autosomal recessive disorder characterized by intestinal hyperabsorption of all sterols, including cholesterol and plant and shellfish sterols, and impaired ability to excrete sterols into bile. Patients frequently develop tendon and tuberous xanthomas, accelerated atherosclerosis, and premature CAD. They have identified multiple mutations in the $A B C G 8$ gene and mutations in the $A B C G 5$ gene in patients with sitosterolemia. The $A B C G 5$ and $A B C G 8$ genes normally cooperate to limit intestinal absorption and to promote biliary excretion of sterols, and mutated forms of these transporters predispose to sterol accumulation, $\mathrm{FH}$ and atherosclerosis $[81,83]$.

ABCA1 Gene. The $A B C A 1$ gene belongs to a group of genes called the ATP-binding cassette family located at 9q31. It moves phospholipids and cholesterol across the cell membrane for the formation ofHDL-c, and has an important role in the initial phase of reverse cholesterol transport. Mutations in this gene have been associated with Tangier disease, an autosomal-recessive disorder characterized by deposition of cholesterol esters in organs, and familial HDL deficiency, low cellular cholesterol efflux due to mutant $A B C A 1$ that leads to reduced apolipoprotein A-I stability and rapid catabolism of HDL-c [84-87].

PCSK9 Inhibitor Therapy. Proprotein convertase subtilisin kexin type 9 (PCSK9) inhibitors are promising therapies that inhibit the degradation of LDL receptors in the hepatocyte and thus increase LDL-c uptake from the blood. Among the various monoclonal antibodies developed against PCSK9, two stand out: evolocumab and alirocumab, these have been approved for clinical use, both fully human monoclonal antibodies are administered subcutaneously. Three large randomized, double-blind, placebo-controlled studies have provided cardiovascular results evaluating PCSK9 therapy with inhibitors, these studies are: FOURIER trial, SPIRE-1 and SPIRE-2 trials, and ODYSSEY Outcomes trial. The PCSK9 inhibitors are now proven to be valid additions to the clinicians' armamentarium for the treatment of dyslipidemia. These drugs reduce plasma LDL-c level by approximately $60.0 \%$, significantly reduce the risk of major vascular events and have no adverse effects except for injection-site reactions. These therapeutics could offer the opportunity to intervene earlier and more easily to treat dyslipidemia and potentially to largely eradicate coronary disease [88].

Final Considerations. As final considerations we can mention that the PCSK9 gene has an important role in the development of primary dyslipidemias, mainly $\mathrm{FH}$, the main risk factor for disease is LDL-c. Currently, the treatment pharmacological by choice to reduce LDL-c are statins, however, it has been observed that these have been insufficient to eliminate cardiovascular risk, especially in subjects with primary forms of hypercholesterolemia related to genetic mutations, or intolerant to statins, and new pharmacological therapies have drawn attention to the inhibition of this gene. It is necessary to continue researching even more because PSCK9 is not the only gene that has participation in these pathologies, which is why it requires integration and collaboration between medical specialists, geneticists and molecular biologists, being essential for adequate advice to people at risk for any pathology, always taking care of the ethical aspects that these studies involve.

Acknowledgments. Authors' contributions: I.A. García-Montalvo, A.D. Pérez-Santiago, J.J. Alpuche Osorno, M.A Sánchez Medina and D. Matías-Pérez participated in the concept of study, design, writing and critical review of the manuscript. This manuscript is a review article that addresses the role played by the PCSK 9 gene in primary dyslipidemia, as well as the description of other genes in the pathology.

Declaration of Interest. The authors report no conflicts of interest. The authors alone are responsible for the content and writing of this article.

Ethical Responsibilities. Protection of people and animals. The authors declare that no experiments have been conducted on humans or animals for this research.

Confidentiality of the Data. The authors declare that patient data does not appear in this article. 


\section{REFERENCES}

1. Díaz-Aragón A, Fernández-Barros CL, EncisoMuñoz JM, Ceballos-Reyes G, Gutiérrez-Salmeán G, León Hernández FJ, et al.e. Posicionamiento en torno al diag-nóstico y tratamiento de las dislipidemias. Rev Mex Cardiol. 2018; 29(3): 148-168.

2. World Health Organization. Cardiovascular diseases (CVDs). [http://www.who.int/news-room/fact-sheets/ detail/cardiovasculard-diseases-(cvds); accessed June 13 2020].

3. Barquera S, Pedroza-Tobías A, Medina C, HernándezBarrera L, Bibbins-Domingo K, Lozano R, et al. Global overview of the epidemiology of atherosclerotic cardiovascular disease. Arch Med Res. 2015; 46(5): 328-338

4. Nowbar AN, Gitto M, Howard JP, Francis DP, AlLamee R. Mortality from ischemic heart disease. Circ Cardiovasc Qual Outcomes. 2019; 12(6): e005375.

5. Martinez-Sanchez C, Borrayo G, Carrillo J, Juarez U, Quintanilla J, Jerjes-Sanchez C. Clinical management and hospital outcomes of acute coronary syndrome patients in Mexico: The Third National Registry of Acute Coronary Syndromes (RENASICA III). Arch Cardiol México. 2016; 86(3): 221-232.

6. Canalizo-Miranda E, Favela-Pérez EA, Salas-Anaya JA, Gómez-Díaz R, Jara-Espino R, Del L, et al. Guía de práctica clínica Diagnóstico y tratamiento de las dislipidemias. Rev Med Inst Mex Seguro Soc. 2013; 51(6): 700-709.

7. McEvoy JW, Whelton SP, Blumenthal RS. Dyslipidemia. In: Bakris GL, Sorrentino MJ, Editors. Hypertension: A Companion to Braunwald's Heart Disease, 3rd ed. Chicago, IL, USA: Elsevier, 2018: 353-360.

8. Urbina EM, Daniels SR. Hyperlipidemia. In: Slap GB, Editor. Adolescent Medicine. Philadelphia, PA, USA: Mosby, 2008: 90-96.

9. Hurtubise J, McLellan K, Durr K, Onasanya O, Nwabuko D, Ndisang JF. The different facets of dyslipidemia and hypertension in atherosclerosis. Curr Atheroscler Rep. [Internet] 2016; 18(12): 82.

10. Matías-Pérez D, Pérez-Campos E, Antonio GarcíaMontalvo I, Antonio I, Montalvo G. A genetic view of familial hypercholesterolemia. Nutr Hosp. 2015; 32(6): 2421-2426.

11. Smith LC, Massey JB, Sparrow JT, Gotto AM, Pownall HJ. Structure and dynamics of human plasma lipoproteins. In: Bakris GL, Sorrentino MJ, Editors. Supramolecular Structure and Function. Boston, MA, USA: Springer US; 1983; 205-244.
12. Barter PJ, Brewer HB, Chapman MJ, Hennekens CH, Rader DJ, Tall AR. Cholesteryl ester transfer protein. Arterioscler Thromb Vasc Biol. 2003; 23(2): 160-167.

13. Yamashita T, Lakota K, Taniguchi T, Yoshizaki A, Sato $\mathrm{S}$, Hong $\mathrm{W}$, et al. An orally-active adiponectin receptor agonist mitigates cutaneous fibrosis, inflammation and microvascular pathology in a murine model of systemic sclerosis. Sci Rep. 2018; 8(1): 11843.

14. Huang Q, Qin L, Dai S, Zhang H, Pasula S, Zhou $\mathrm{H}$, et al. AIP1 suppresses atherosclerosis by limiting hyperlipidemia-induced inflammation and vascular endothelial dysfunction. Arterioscler Thromb Vasc Biol. 2013; 33(4): 795-804.

15. Kuivenhoven JA, Hegele RA. Mining the genome for lipid genes. Biochim Biophys Acta. 2014; 1842(10): 1993-2009.

16. Varret M, Rabès JP, Saint-Jore B, Cenarro A, Marinoni $\mathrm{JC}$, Civeira F, et al. A third major locus for autosomal dominant hypercholesterolemia maps to 1p34.1-p32. Am J Hum Genet. 1999; 64(5): 1378-1387.

17. Akioyamen LE, Genest J, Shan SD, Reel RL, Albaum $\mathrm{JM}, \mathrm{Chu} \mathrm{A}$, et al. Estimating the prevalence of heterozygous familial hypercholesterolaemia: A systematic review and meta-analysis. BMJ Open. 2017; 7(9): e016461.

18. Nassoury N, Blasiole DA, Tebon Oler A, Benjannet $\mathrm{S}$, Hamelin J, Poupon V, et al. The cellular trafficking of the secretory proprotein convertase PCSK9 and its dependence on the LDLR. Traffic. 2007; 8(6): 718-732.

19. Luo Y, Warren L, Xia D, Jensen H, Sand T, Petras $\mathrm{S}$, et al. Function and distribution of circulating human PCSK9 expressed extrahepatically in transgenic mice. J Lipid Res. 2009; 50(8): 1581-1588.

20. Dijk W, Le May C, Cariou B. Beyond LDL: What role for PCSK9 in triglyceride-rich lipoprotein metabolism? Trends Endocrinol Metab. 2018; 29(6): 420-434.

21. Lalanne F, Lambert G, Amar MJA, Chétiveaux M, Zaïr Y, Jarnoux AL, et al. Wild-type PCSK9 inhibits LDL clearance but does not affect apoB-containing lipoprotein production in mouse and cultured cells. J Lipid Res. 2005; 46(6): 1312-1319.

22. Seidah NG, Benjannet $\mathrm{S}$, Wickham L, Marcinkiewicz J, Bélanger Jasmin S, Stifani S, et al. The secretory proprotein convertase neural apoptosis-regulated convertase 1 (NARC-1): Liver regeneration and neuronal differentiation. Proc Natl Acad Sci USA. 2003; 100(3): 928-933.

23. Gustafsen C, Kjolby M, Nyegaard M, Mattheisen $\mathrm{M}$, Lundhede J, Buttenschøn H, et al. The hypercho- 
lesterolemia-risk gene SORT1 facilitates PCSK9 secretion. Cell Metab. 2014; 19(2): 310-318.

24. Schmidt RJ, Beyer TP, Bensch WR, Qian YW, Lin A, Kowala M, et al. Secreted proprotein convertase subtili$\sin$ / kexin type 9 reduces both hepatic and extrahepatic low-density lipoprotein receptors in vivo. Biochem Biophys Res Commun. 2008; 370(4): 634-640.

25. Marian AJ. PCSK 9 as a therapeutic target in atherosclerosis. Curr Atheroscler Rep. 2010; 12(3): 151-154.

26. Seidah NG. PCSK9 as a therapeutic target of dyslipidemia. Expert Opin Ther Targets. 2009; 13(1): 19-28.

27. Sabatine MS. Proprotein convertase subtilisin/kexin type 9 (PCSK9) inhibitors: Comparing and contrasting guidance across the Atlantic. Eur Heart J. 2017; 38(29): 2256-2258.

28. Li S, Zhang Y, Xu R-X, Guo Y-L, Zhu C-G, Wu N-Q, et al. Proprotein convertase subtilisin-kexin type 9 as a biomarker for the severity of coronary artery disease. Ann Med. 2015; 47(5): 386-393.

29. Alonso R, Mata P, Muñiz O, Fuentes-Jimenez F, Díaz JL, Zambón D, et al. PCSK9 and lipoprotein (a) levels are two predictors of coronary artery calcification in asymptomatic patients with familial hypercholesterolemia. Atherosclerosis. 2016; 254: 249-253.

30. Kim JH. Letter: Serum levels of PCSK9 are associated with coronary angiographic severity in patients with acute coronary syndrome (Diabetes Metab J. 2018;42:207-14). Diabetes Metab J. 2018; 42(4): 348-349.

31. Tang Z, Li T, Peng J, Zheng J, Li T, Liu L, et al. PCSK9: A novel inflammation modulator in atherosclerosis? J Cell Physiol. 2019;234(3): 2345-2355.

32. Hopkins PN, Defesche J, Fouchier SW, Bruckert E, Luc G, Cariou B, et al. Characterization of autosomal dominant hypercholesterolemia caused by PCSK9 cain of function mutations and its specific treatment with alirocumab, a PCSK9 monoclonal antibody. Circ Cardiovasc Genet. 2015; 8(6): 823-831.

33. Cohen J, Pertsemlidis A, Kotowski IK, Graham R, Garcia CK, Hobbs HH. Low LDL cholesterol in individuals of African descent resulting from frequent nonsense mutations in PCSK9. Nat Genet. 2005; 37(2): 161-165.

34. Miyake Y, Kimura R, Kokubo Y, Okayama A, Tomoike H, Yamamura T, et al. Genetic variants in PCSK9 in the Japanese population: Rare genetic variants in PCSK9 might collectively contribute to plasma LDL cholesterol levels in the general population. Atherosclerosis. 2008; 196(1): 29-36.
35. Zhao Z, Tuakli-Wosornu Y, Lagace TA, Kinch L, Grishin NV, Horton JD, et al. Molecular characterization of loss-of-function mutations in PCSK9 and identification of a compound heterozygote. Am J Hum Genet. 2006; 79(3): 514-523.

36. Abifadel M, Varret M, Rabès J-P, Allard D, Ouguerram $\mathrm{K}$, Devillers $\mathrm{M}$, et al. Mutations in PCSK9 cause autosomal dominant hypercholesterolemia. Nat Genet. 2003; 34(2): 154-156.

37. Timms KM, Wagner S, Samuels ME, Forbey K, Goldfine H, Jammalapati S, et al. A mutation in PCSK9 causing autosomal-dominant hypercholesterolemia in a Utah pedigree. Hum Genet. 2004; 114(4): 349-353.

38. Hunt SC, Hopkins PN, Bulka K, McDermott MT, Thorne TL, Wardell BB, et al. Genetic localization to chromosome $1 \mathrm{p} 32$ of the third locus for familial hypercholesterolemia in a Utah kindred. Arterioscler Thromb Vasc Biol. 2000; 20(4): 1089-1093.

39. Leren TP. Mutations in the PCSK9 gene in Norwegian subjects with autosomal dominant hypercholesterolemia. Clin Genet. 2004; (4): 419-422.

40. Sun XM, Eden ER, Tosi I, Neuwirth CK, Wile D, Naoumova RP, et al. Evidence for effect of mutant PCSK9 on apolipoprotein B secretion as the cause of unusually severe dominant hypercholesterolaemia. Hum Mol Genet. 2005; 14(9): 1161-1169.

41. Bourbon M, Alves AC, Medeiros AM, Silva S, Soutar AK. Familial hypercholesterolaemia in Portugal. Atherosclerosis. 2008; 196(2): 633-642.

42. Allard D, Amsellem S, Abifadel M, Trillard M, Devillers M, Luc G, et al. Novel mutations of the PCSK9 gene cause variable phenotype of autosomal dominant hypercholesterolemia. Hum Mutat. 2005; 26(5): 497.

43. Homer VM, Marais AD, Charlton F, Laurie AD, Hurndell N, Scott R, et al. Identification and characterization of two non-secreted PCSK9 mutants associated with familial hypercholesterolemia in cohorts from New Zealand and South Africa. Atherosclerosis. 2008; 196(2): 659-666.

44. Abifadel M, Rabès J-P, Devillers M, Munnich A, Erlich D, Junien C, et al. Mutations and polymorphisms in the proprotein convertase subtilisin kexin 9 (PCSK9) gene in cholesterol metabolism and disease. Hum Mutat. 2009; 30(4): 520-529.

45. Iacocca MA, Wang J, Sarkar S, Dron JS, Lagace $\mathrm{T}$, McIntyre AD, et al. Whole-gene duplication of PCSK9 as a novel genetic mechanism for severe familial hypercholesterolemia. Can J Cardiol. 2018; 34(10): 1316-1324. 
46. Zambrano T, Hirata MH, Cerda Á, Dorea EL, Pinto GA, Gusukuma MC, et al. Impact of 3'UTR genetic variants in PCSK9 and LDLR genes on plasma lipid traits and response to atorvastatin in Brazilian subjects: A pilot study. Int J Clin Exp Med. 2015; 8(4): 5978-5988.

47. Robles-Osorio L, Huerta-Zepeda A, Ordóñez ML, Canizales-Quinteros S, Díaz-Villaseñor A, GutiérrezAguilar R, et al. Genetic heterogeneity of autosomal dominant hypercholesterolemia in Mexico. Arch Med Res. 2006; 37(1): 102-108.

48. Mehta R, Zubirán R, Martagón AJ, Vazquez-Cárdenas A, Segura-Kato Y, Tusié-Luna MT, et al. The panorama of familial hypercholesterolemia in Latin America: A systematic review. J Lipid Res. 2016; 57(12): 2115-2129.

49. Garg A, Fazio S, Duell PB, Baass A, Udata C, Joh T, et al. Molecular characterization of familial hypercholesterolemia in a North American cohort. J Endocr Soc. 2020; 4(1): 1-16.

50. Sánchez-Hernández RM, Tugores A, Nóvoa FJ, BritoCasillas Y, Expósito-Montesdeoca AB, Garay P, et al. The island of Gran Canaria: A genetic isolate for familial hypercholesterolemia. J Clin Lipidol. 2019; 13(4): 618-626.

51. Abifadel M, Rabès JP, Jambart S, Halaby G, GannagéYared MH, Sarkis A, et al. The molecular basis of familial hypercholesterolemia in Lebanon: Spectrum of LDLR mutations and role of PCSK9 as a modifier gene. Hum Mutat. 2009;30(7): E682-E691.

52. Yang KC, Su YN, Shew JY, Yang KY, Tseng WK, Wu $\mathrm{CC}$, et al. LDLR and ApoB are major genetic causes of autosomal dominant hypercholesterolemia in a taiwanese population. J Formos Med Assoc. 2007; 106(10): 799-807.

53. Pisciotta L, Oliva $\mathrm{CP}$, Cefalù $\mathrm{AB}$, Noto $\mathrm{D}$, Bel-locchio A, Fresa R, et al. Additive effect of mutations in LDLR and PCSK9 genes on the phenotype of familial hypercholesterolemia. Atherosclerosis. 2006; 186(2): 433-440.

54. Noguchi T, Katsuda S, Kawashiri M-A, Tada H, Nohara A, Inazu A, et al. The E32K variant of PCSK9 exacerbates the phenotype of familial hypercholesterolaemia by increasing PCSK9 function and concentration in the circulation. Atherosclerosis. 2010; 210(1): 166-172.

55. Roche-Molina M, Sanz-Rosa D, Cruz FM, GarcíaPrieto J, López S, Abia R, et al. Induction of sustained hypercholesterolemia by single adeno-associated virus-mediated gene transfer of mutant hPCSK9. Arterioscler Thromb Vasc Biol. 2015; 35(1): 50-59.
56. Bjørklund MM, Hollensen AK, Hagensen MK, Dagnæs-Hansen F, Christoffersen C, Mikkelsen JG, et al. Induction of atherosclerosis in mice and hamsters without germline genetic engineering. Circ Res. 2014; 114(11): 1684-1689.

57. Goettsch C, Hutcheson JD, Hagita S, Rogers MA, Creager MD, Pham T, et al. A single injection of gain-of-function mutant PCSK9 adeno-associated virus vector induces cardiovascular calcification in mice with no genetic modification. Atherosclerosis. 2016; 251: 109-118.

58. Denis M, Marcinkiewicz J, Zaid A, Gauthier D, Poirier $\mathrm{S}$, Lazure $\mathrm{C}$, et al. Gene inactivation of proprotein convertase subtilisin/kexin type 9 reduces atherosclerosis in mice. Circulation. 2012; 125(7): 894-901.

59. Al-Mashhadi RH, Sørensen CB, Kragh PM, Christoffersen C, Mortensen MB, Tolbod LP, et al. Familial hypercholesterolemia and atherosclerosis in cloned minipigs created by DNA transposition of a human PCSK9 gain-of-function mutant. Sci Transl Med. 2013; 5(166): 1-10.

60. Hedayat AF, Park K-H, Kwon T-G, Woollard JR, Jiang K, Carlson DF, et al. Peripheral vascular atherosclerosis in a novel PCSK9 gain-of-function mutant Ossabaw miniature pig model. Transl Res. 2018; 192: 30-45.

61. Miller M, Kwiterovich PO. Isolated low HDLcholesterol as an important risk factor for coronary heart disease. Eur Heart J. 1990; 11(suppl H): 9-14.

62. Puntoni M, Sbrana F, Bigazzi F, Sampietro T. Tangier disease: Epidemiology, pathophysiology, and management. Am J Cardiovasc Drugs. 2012; 12(5): 303-311.

63. Savel J, Lafitte M, Pucheu Y, Pradeau V, Tabarin A, Couffinhal T. Very low levels of HDL cholesterol and atherosclerosis, a variable relationship--a review of LCAT deficiency. Vasc Health Risk Manag. 2012; 8: 357-361.

64. Yuan F, Guo L, Park KH, Woollard JR, Taek-Geun $\mathrm{K}$, Jiang $\mathrm{K}$, et al. Ossabaw pigs with a PCSK9 fainof-function mutation develop accelerated coronary atherosclerotic lesions: A novel model for preclinical studies. J Am Heart Assoc. 2018; 7(6): e006207.

65. Duff CJ, Hooper NM. PCSK9: An emerging target for treatment of hypercholesterolemia. Expert Opin Ther Targets. 2011; 15(2): 157-168.

66. Soria LF, Ludwig EH, Clarke HR, Vega GL, Grundy SM, McCarthy BJ. Association between a specific apolipoprotein B mutation and familial defective apolipoprotein B-100. Proc Natl Acad Sci USA. 1989; 86(2): 587-591. 
67. Myant NB. Familial defective apolipoprotein B-100: A review, including some comparisons with familial hypercholesterolaemia. Atherosclerosis. 1993; 104(12): $1-18$.

68. Dugaiczyk A, Haron JA, Stone EM, Dennison OE, Rothblum KN, Schwartz RJ. Cloning and sequencing of a deoxyribonucleic acid copy of glyceraldehyde3-phosphate dehydrogenase messenger ribonucleic acid isolated from chicken muscle. Biochemistry. 1983; 22(7): 1605-1613.

69. Eden ER, Naoumova RP, Burden JJ, McCarthy MI, Soutar AK. Use of homozygosity mapping to identify a region on chromosome 1 bearing a defective gene that causes autosomal recessive homozygous hypercholesterolemia in two unrelated families. Am J Hum Genet. 200; 68(3): 653-660.

70. Soutar AK, Naoumova RP, Traub LM. Genetics, clinical phenotype, and molecular cell biology of autosomal recessive hypercholesterolemia. Arterioscler Thromb Vasc Biol. 2003; 23(11): 1963-1970.

71. Canizales-Quinteros S, Aguilar-Salinas CA, HuertasVázquez A, Ordóñez-Sánchez ML, Rodríguez-Torres M, Venturas-Gallegos JL, et al. A novel ARH splice site mutation in a Mexican kindred with autosomal recessive hypercholesterolemia. Hum Genet. 2005; 116(1-2): 114-120.

72. Harada K, Miyamoto Y, Morisaki H, Ohta N, Yamanaka I, Kokubo Y, et al. A novel Thr56Met mutation of the autosomal recessive hypercholesterolemia gene associated with hypercholesterolemia. J Atheroscler Thromb. 2010; 17(2): 131-140.

73. Awan Z, Choi HY, Stitziel N, Ruel I, Bamimore MA, Husa R, et al. APOE p.Leu167del mutation in familial hypercholesterolemia. Atherosclerosis. 2013; 231(2): 218-222.

74. Sharifi M, Futema M, Nair D, Humphries SE. Polygenic hypercholesterolemia and cardiovascular disease risk. Curr Cardiol Rep. 2019; 21(6): 43.

75. Stoll M, Dell'Oca N. Genética de la hipercolesterolemia familiar. Rev Urug Cardiol. 2019; 34(3): 324-332.

76. Bourbon M, Alves AC, Sijbrands EJ. Low-density lipoprotein receptor mutational analysis in diagnosis of familial hypercholesterolemia. Curr Opin Lipidol. 2017; 8(2): 120-129.

77. Graham CA, McIlhatton BP, Kirk CW, Beattie ED, Lyttle K, Hart P, et al. Genetic screening protocol for familial hypercholesterolemia which includes splicing defects gives an improved mutation detection rate. Atherosclerosis. 2005; 182(2): 331-340.
78. Nose D, Hori M, Miyamoto Y, Imaizumi S, HaradaShiba M, Saku K, et al. Discontinuation of LDL apheresis with evolocumab in an $\mathrm{FH}$ patient with a duplication of exon 2-6 in the LDLR gene. J Cardiol Cases. 2019; 19(2): 55-58.

79. Cheng S, Wu Y, Wen W, An M, Gao Y, Wang L, et al. Independent severe cases of heterozygous familial hypercholesterolemia caused by the W483X and novel W483G mutations in the low-density lipoprotein receptor gene that were clinically diagnosed as homozygous cases. Genet Test Mol Biomarkers. 2019; 23(6): 401-408.

80. Goldstein JL, Schrott HG, Hazzard WR, Bierman EL, Motulsky AG. Hyperlipidemia in Coronary Heart Disease II. Genetic analysis of lipid levels in 176 families and delineation of a new inherited disorder, combined hyperlipidemia. J Clin Invest. 1973; 52(7): 1544-1568.

81. Berge KE, Tian H, Graf GA, Yu L, Grishin NV, Schultz $\mathrm{J}$, et al. Accumulation of dietary cholesterol in sitosterolemia caused by mutations in adjacent $\mathrm{ABC}$ transporters. Science. 2000; 290(5497): 1771-1775.

82. Rios J, Stein E, Shendure J, Hobbs HH, Cohen JC. Identification by whole-genome resequencing of gene defect responsible for severe hypercholesterolemia. Hum Mol Genet. 2010; 19(22): 4313-4318.

83. Lee MH, Lu K, Hazard S, Yu H, Shulenin S, Hidaka $\mathrm{H}$, et al. Identification of a gene, ABCG5, important in the regulation of dietary cholesterol absorption. Nat Genet. 2001; 27(1): 79-83.

84. Soumian S, Albrecht C, Davies AH, Gibbs RG. ABCA1 and atherosclerosis. Vasc Med. 2005; 10(2): 109-119.

85. Olson MV. Human genetic individuality. Annu Rev Genomics Hum Genet. 2012; 13: 1-27.

86. Ho Hong S, Rhyne J, Zeller K, Miller M. Novel ABCA1 compound variant associated with HDL cholesterol deficiency. Biochim Biophys Acta. 2002; 1587(1): 60-64.

87. Ahmadzadeh A, Azizi F. Genes Associated with low serum high-density lipoprotein cholesterol. Arch Iran Med. 2014; 17(6): 444-450.

88. Sabatine MS. PCSK9 inhibitors: Clinical evidence and implementation. Nat Rev Cardiol. 2019; 16(3): 155-165. 
